\title{
The Study on Long-Term Toxicity of D-Psicose in Rats
}

\author{
Kanako Yagi, and Tatsuhiro Matsuo* \\ Faculty of Agriculture, Kagawa University, Ikenobe, Miki-cho, Kita-gun, Kagawa 761-0795, Japan
}

Received 1 July, 2008; Accepted 24 July, 2008

\begin{abstract}
Summary D-Psicose is a rare sugar present in small quantities in natural products. In a previous study, we showed that D-psicose suppresses plasma glucose increases and reduces body fat accumulation in rats. Based on acute toxicity testing in rats, D-psicose is classified as an ordinary substance $\left(L D_{50}=16 \mathrm{~g} / \mathrm{kg}\right.$ ). Elucidating the effects of long term feeding of $D$ psicose in rats will be essential prior to its utilization as a physiologically functional food. In this study, male Wistar rats (3 weeks old) were fed diets containing 3\% D-psicose or sucrose for 12-18 months. The rats actually ingested $1.28 \mathrm{~g} / \mathrm{kg}$ body weight per day D-psicose or $1.22 \mathrm{~g} / \mathrm{kg}$ body weight per day of sucrose. Body weight gain and intra-abdominal adipose tissue weight in rats fed the D-psicose diet for 18 months were significantly lower than those in rats fed the sucrose diet. Relative weights of liver and kidney were significantly higher in the Dpsicose group than in the sucrose group. However, no gross pathological findings were evident at dietary doses of $3 \%$ D-psicose or correlated with hypertrophy of liver and kidney. No clinical chemical test value was suggestive of overt D-psicose treatment-related toxicity. Therefore, the present study found no adverse effects at 3\% D-psicose in the diet.
\end{abstract}

Key Words: D-psicose, sucrose, long-term toxicity, chemical tests, rat

\section{Introduction}

D-psicose (D-ribo-2-hexulose), a C-3 epimer of Dfructose, is a "rare sugar" present in small quantities in commercial mixtures of D-glucose and D-fructose obtained from hydrolysis of sucrose or isomerization of D-glucose [1]. D-psicose is also present in processed cane and beet molasses [2], and is found in wheat [3], Itea plants [4], and in the antibiotic psicofranine [5]. Because of the very small amounts of D-psicose in natural products, few studies have examined D-psicose metabolism in animals.

Recently, we developed a new method to produce Dpsicose enzymatically on a large scale [6,7], making it possible to conduct studies of bioactivity and applications in food and medicine. Examining the effects of D-psicose on glucose and lipid metabolisms, we found that D-psicose is a

\footnotetext{
*To whom correspondence should be addressed.

Tel/Fax: 81-87-891-3082

E-mail:matsuo@ag.kagawa-u.ac.jp
}

sweet monosaccharaide that provides no energy to growing rats and leads to less intra-abdominal fat accumulation than D-glucose and D-fructose in rats [8,9]. In addition, we have suggested that supplemental D-psicose can lower plasma glucose levels [10].

Based on acute toxicity testing in rats, D-psicose is classified as an ordinary substance; the LD50 value was $16 \mathrm{~g} / \mathrm{kg}$ orally in rats [11]. D-psicose, which is contained in foods such as fruit juice and fruit cereal, is derived from D-fructose in the cooking process $[2,12]$. Thus, most humans ingest a limited amount of D-psicose on a daily basis. However, the effects of long-term feeding of Dpsicose must be elucidated prior to utilization as a physiologically functional food.

In this study, to assess D-psicose safety, oral 12-month and 18-month toxicity studies were conducted with rats at dietary doses of $3 \% \mathrm{D}$-psicose. The objective was to determine whether or not D-psicose can be used as a food. 


\section{Materials and Methods}

All procedures involving animals were approved by the Animal Care Committee of the Kagawa University.

\section{Animals and experimental diets}

Thirty-six male Wistar rats (3 weeks old) were obtained from Japan SLC (Shizuoka, Japan). They were fed CE-2, a commercial rodent diet (CLEA, Tokyo, Japan) and water $a d$ libitum until they were 4 weeks old. They were caged individually at $22 \pm 2^{\circ} \mathrm{C}$, with light from 08:00 to $20: 00 \mathrm{~h}$. The rats were randomly divided into two groups of 18 (the sucrose and D-psicose groups). We adopted sucrose as a control of D-psicose because sucrose is a most popular sweet carbohydrate and is used in many studies as control saccharide [13-15]. The experimental diets were 3\% sucrose or D-psicose added to the CE-2. The amount of test carbohydrates $(3 \%)$ was decided in reference to previous studies concerning sucralose with the $\mathrm{LD}_{50}$ level $(16 \mathrm{~g} / \mathrm{kg}$ weight) same as D-psicose $[11,16,17]$. Each group of rats was given free access to the food and water for 12 or 18 months. Dpsicose was donated by the Rare Sugar Center of Kagawa University. Sucrose was purchased from Wako Pure Chemical Industries (Osaka, Japan).

\section{Experimental Design}

After 12 months of feeding, 8 rats in each group were fasted $4.5 \mathrm{~h}$ from $06: 00 \mathrm{~h}$, then anesthetized with intraperitoneal administration of sodium pentobarbital. Blood was collected from the abdominal aorta for clinical hematological analysis and to obtain serum for chemical analysis. The rats were allowed to exsanguinate. The remainders of the rats (10 rats in each group) were killed at the end of 18 months in a similar manner. The brain, heart, lungs, liver, pancreas, kidneys, adrenals, spleen, testicles, intra-abdominal adipose tissues (epididymal, perirenal and mesenteric) and muscle tissues (soleus, gastrocnemius and plantarius) were quickly removed and weighed. Parts of the liver and kidney were preserved in $10 \%$ neutral buffered formalin for histopathological examinations. The stomach, small intestine, large intestine and cecum were also quickly removed and weighed. In addition, the small and large intestine length, surface area and cecal content weight were measured.

\section{Analysis}

The following hematological and clinical chemistry parameters were evaluated platelet count (PLT), hemoglobin $(\mathrm{Hb})$, erythrocyte count (RBC), leukocyte count (WBC), hematocrit (HCT), mean corpuscular volume (MCV), mean corpuscular hemoglobin (MCH), mean corpuscular hemoglobin concentration (MCHC), glucose (GLU), insulin (ISL), triglycerides (TG), free fatty acids (FFA), total cholesterol (CHO), aspartate aminotransferase (AST), alanine amino- transferase (ALT), total bilirubin (TBIL), direct bilirubin (DBIL), indirect bilirubin (IBIL), creatinine (CREA), urea nitrogen (BUN), uric acid (UA), albumin (ALBU), total protein (TP), ratio of albumin and globulin (A/G), lipid peroxide (LPO), $\mathrm{Ca}$, and Fe. Hematological analysis was requested from SRL Co., Ltd. (Tokyo, Japan). Concentrations of serum glucose, triglycerides and peroxide lipid were determined by methods reported previously [18-20]. Serum insulin concentration was determined using a kit (Rat Insulin EIA System, Amersham Bioscience, Tokyo, Japan). Serum iron concentration was measured by flame atomic absorption spectrophotometry (AAS Z-5000, Hitachi, Tokyo, Japan) after diluted samples with $0.1 \mathrm{M} \mathrm{HNO}_{3}$. Other analyses of clinical chemistry were determined using a kit (Wako Pure Chemical Industries, Osaka, Japan). Evaluation of histopathological examinations was requested from Fuji Biomedix (Yamanashi, Japan). Then, histopathological levels in each rat were subjectively quantified as follows score: $(-; 0, \pm ; 1,+; 2,++; 3,+++; 4)$.

\section{Statistical analysis}

All values were expressed as mean \pm SD. Statistical analysis of differences between the sucrose and D-psicose groups was performed with Student's $t$ test. Statistical significance was set at $p$ value of $<0.05$. All analyses were performed with a commercially available statistical package (Stat View J-5.0, SAS Institute Inc., Cary, NC).

\section{Results}

Body and tissue weights, energy intake and digestive tract size

Results of body and tissue weights, energy intake and digestive tract size in rats fed for 12 or 18 months are presented in Tables 1 and 2, respectively. Final body weight, weight gain and energy intake did not differ between the sucrose and the D-psicose group at 12 months (Table 1). At 18 months, final body weight and weight gain in the Dpsicose group were significantly lower than in the sucrose group, through energy intake did not differ between the 2 groups (Table 1 ). The rats actually ingested $1.28 \mathrm{~g} / \mathrm{kg}$ body weight per day D-psicose or $1.22 \mathrm{~g} / \mathrm{kg}$ body weight per day of sucrose. Livers and kidneys at 12 months were significantly heavier in the D-psicose group than in the sucrose group, but no differences were observed in any other tissue weights (Table 1). Livers and kidneys at 18 months were also significantly heavier in the D-psicose group than in the sucrose group, and higher weights were also observed in brains, lungs and pancreas in the D-psicose group compared to the sucrose group (Table 1). In contrast, relative intraabdominal adipose tissues at 18 months were significantly lighter in the D-psicose group than in the sucrose group (Table 1). Digestive tract size in rats fed for 12 months did 
Table 1. Body weight, Energy intake and Tissue weights

\begin{tabular}{|c|c|c|c|c|c|}
\hline \multirow{2}{*}{ Groups } & & \multicolumn{2}{|c|}{12 months } & \multicolumn{2}{|c|}{18 months } \\
\hline & & Sucrose & D-Psicose & Sucrose & D-Psicose \\
\hline Initial weight & (g) & $87 \pm 8$ & $91 \pm 2$ & $82 \pm 10$ & $79 \pm 12$ \\
\hline Final weight & (g) & $446 \pm 13$ & $435 \pm 17$ & $405 \pm 15$ & $346 \pm 28 * *$ \\
\hline Weight gain & (g) & $360 \pm 7$ & $344 \pm 17$ & $322 \pm 13$ & $285 \pm 22 * *$ \\
\hline Energy intake & (kcal/day) & $62.7 \pm 2.8$ & $64.6 \pm 1.7$ & $59.5 \pm 3.0$ & $60.2 \pm 4.2$ \\
\hline \multicolumn{6}{|l|}{ Tissue weights ${ }^{\dagger}$} \\
\hline Brain & $(\mathrm{g} / 100 \mathrm{~g})$ & $0.45 \pm 0.02$ & $0.46 \pm 0.02$ & $0.50 \pm 0.02$ & $0.54 \pm 0.04 * *$ \\
\hline Heart & $(\mathrm{g} / 100 \mathrm{~g})$ & $0.21 \pm 0.01$ & $0.21 \pm 0.01$ & $0.21 \pm 0.01$ & $0.22 \pm 0.02$ \\
\hline Lungs & $(\mathrm{g} / 100 \mathrm{~g})$ & $0.26 \pm 0.01$ & $0.26 \pm 0.02$ & $0.28 \pm 0.02$ & $0.31 \pm 0.01^{*}$ \\
\hline Liver & $(\mathrm{g} / 100 \mathrm{~g})$ & $3.26 \pm 0.18$ & $3.69 \pm 0.19^{* *}$ & $3.12 \pm 0.27$ & $3.84 \pm 0.24 * *$ \\
\hline Pancreas & $(\mathrm{g} / 100 \mathrm{~g})$ & $0.12 \pm 0.02$ & $0.13 \pm 0.03$ & $0.13 \pm 0.02$ & $0.17 \pm 0.02 * *$ \\
\hline Kidneys & $(\mathrm{g} / 100 \mathrm{~g})$ & $0.63 \pm 0.03$ & $0.74 \pm 0.03^{* *}$ & $0.64 \pm 0.03$ & $0.81 \pm 0.05 * *$ \\
\hline Adrenals & $(\mathrm{g} / 100 \mathrm{~g})$ & $0.01 \pm 0.00$ & $0.01 \pm 0.00$ & $0.01 \pm 0.00$ & $0.01 \pm 0.00$ \\
\hline Spleen & $(\mathrm{g} / 100 \mathrm{~g})$ & $0.20 \pm 0.03$ & $0.21 \pm 0.04$ & $0.23 \pm 0.01$ & $0.25 \pm 0.04$ \\
\hline Testicles & $(\mathrm{g} / 100 \mathrm{~g})$ & $0.71 \pm 0.03$ & $0.71 \pm 0.07$ & $1.02 \pm 0.30$ & $0.92 \pm 0.10$ \\
\hline Intra-adipose tissues & $(\mathrm{g} / 100 \mathrm{~g})$ & $8.27 \pm 0.62$ & $8.17 \pm 0.97$ & $7.63 \pm 0.30$ & $5.79 \pm 1.04 * *$ \\
\hline Muscle tissues & $(\mathrm{g} / 100 \mathrm{~g})$ & $0.05 \pm 0.00$ & $0.05 \pm 0.00$ & $0.05 \pm 0.00$ & $0.06 \pm 0.01$ \\
\hline
\end{tabular}

Values are means \pm SD for $8-10$ rats. ${ }^{*} * *$ Significant difference from the Sucrose group $\left({ }^{*} p<0.05,{ }^{*} p<0.01\right.$, Student's $t$ tests). ${ }^{\dagger}$ Relative tissue weights per $100 \mathrm{~g}$ final body weight.

Table 2. Digestive tracts size

\begin{tabular}{|c|c|c|c|c|c|c|}
\hline \multirow{2}{*}{ Groups } & & & \multicolumn{2}{|c|}{12 months } & \multicolumn{2}{|c|}{18 months } \\
\hline & & & Sucrose & D-Psicose & Sucrose & D-Psicose \\
\hline \multirow[t]{2}{*}{ Stomach } & contents & (g) & $2.33 \pm 0.46$ & $2.52 \pm 0.90$ & $2.91 \pm 0.62$ & $3.59 \pm 1.19$ \\
\hline & weight & (g) & $1.26 \pm 0.08$ & $1.21 \pm 0.15$ & $1.66 \pm 0.24$ & $1.72 \pm 0.18$ \\
\hline \multirow[t]{2}{*}{ Small intestine } & weight & (g) & $2.62 \pm 0.51$ & $2.86 \pm 0.20$ & $3.42 \pm 0.84$ & $4.02 \pm 0.42$ \\
\hline & length & (m) & $1.18 \pm 0.03$ & $1.17 \pm 0.05$ & $1.09 \pm 0.17$ & $1.10 \pm 0.05$ \\
\hline \multirow[t]{2}{*}{ Large intestine } & weight & (g) & $1.05 \pm 0.15$ & $1.20 \pm 0.20$ & $1.33 \pm 0.28$ & $1.26 \pm 0.28$ \\
\hline & length & $\left(\times 10^{-2} \cdot \mathrm{m}\right)$ & $18.7 \pm 1.7$ & $19.8 \pm 1.1$ & $16.8 \pm 1.0$ & $14.5 \pm 3.7$ \\
\hline \multirow[t]{3}{*}{ Cecum } & contents & (g) & $6.62 \pm 0.96$ & $6.84 \pm 0.97$ & $7.09 \pm 0.65$ & $9.07 \pm 1.59^{*}$ \\
\hline & weight & $(\mathrm{g})$ & $0.62 \pm 0.07$ & $0.62 \pm 0.04$ & $0.95 \pm 0.16$ & $0.99 \pm 0.22$ \\
\hline & surface area & $\left(\times 10^{3} \cdot \mathrm{mm}^{2}\right)$ & $3.02 \pm 0.28$ & $3.01 \pm 0.27$ & $2.80 \pm 0.55$ & $3.00 \pm 0.27$ \\
\hline
\end{tabular}

Values are means \pm SD for $8-10$ rats. ${ }^{*}$ Significant difference from the Sucrose group $\left({ }^{*} p<0.01\right.$, Student's $t$ tests).

not differ between the sucrose and the D-psicose group (Table 2). Cecal content weight in rats fed for 18 months was significantly higher in the D-psicose group than in the sucrose group, but no differences were observed in size (Table 2).

\section{Hematological values}

Hematology results in rats fed for 12 or 18 months are presented in Table 3. MCH at 12 months was significantly lower in the D-psicose group than in the sucrose group, but no differences were observed in any of the related hematology values (Table 3). Hb and MCV at 18 months were significantly greater in the D-psicose group than in the sucrose group, but no differences were observed in any of the related hematology values (Table 3).

\section{Clinical chemistry}

Serum chemical analysis results from rats fed for 12 months are presented in Table 4. All chemical values did not differ between the sucrose and D-psicose groups (Table 4).

\section{Histopathological examination}

Histopathological observations of the liver and kidneys are presented in Tables 5 and 6, respectively. Age-related 
Table 3. Hematological values

\begin{tabular}{|c|c|c|c|c|c|}
\hline \multirow{2}{*}{ Groups } & & \multicolumn{2}{|c|}{12 months } & \multicolumn{2}{|c|}{18 months } \\
\hline & & Sucrose & D-Psicose & Sucrose & D-Psicose \\
\hline PLT & $\left(\times 10^{4} / \mathrm{mm}^{3}\right)$ & $76.2 \pm 9.0$ & $83.7 \pm 5.9$ & $76.3 \pm 14.5$ & $75.1 \pm 11.5$ \\
\hline $\mathrm{Hb}$ & $(\mathrm{g} / 100 \mathrm{ml})$ & $14.5 \pm 0.6$ & $14.2 \pm 0.5$ & $15.4 \pm 0.9$ & $14.1 \pm 0.6^{*}$ \\
\hline $\mathrm{RBC}$ & $\left(\times 10^{4} / \mathrm{mm}^{3}\right)$ & $817 \pm 37$ & $838 \pm 21$ & $876 \pm 51$ & $838 \pm 36$ \\
\hline WBC & $(/ \mu \mathrm{l})$ & $2914 \pm 518$ & $2900 \pm 1003$ & $3729 \pm 1533$ & $3560 \pm 1180$ \\
\hline $\mathrm{HCT}$ & $(\%)$ & $45.0 \pm 2.0$ & $45.2 \pm 1.3$ & $47.9 \pm 6.2$ & $45.5 \pm 1.6$ \\
\hline $\mathrm{MCV}$ & $\left(\mu^{3}\right)$ & $55 \pm 1$ & $54 \pm 1$ & $56 \pm 2$ & $54 \pm 1^{*}$ \\
\hline $\mathrm{MCH}$ & (pg) & $18 \pm 1$ & $17 \pm 0 *$ & $17 \pm 1$ & $17 \pm 0$ \\
\hline $\mathrm{MCHC}$ & $(\%)$ & $32 \pm 1$ & $31 \pm 1$ & $31 \pm 1$ & $31 \pm 1$ \\
\hline
\end{tabular}

Values are means \pm SD for $8-10$ rats. *Significant difference from the Sucrose group $\left({ }^{*} p<0.01\right.$, Student's $t$ tests $)$.

Table 4. Clinical chemistry values at 12 months

\begin{tabular}{lccc}
\hline Groups & & Sucose & D-Psicose \\
\hline GLU & $(\mathrm{mg} / 100 \mathrm{ml})$ & $176 \pm 27$ & $170 \pm 20$ \\
ISL & $(\mathrm{ng} / \mathrm{ml})$ & $6.76 \pm 1.35$ & $6.34 \pm 1.12$ \\
TG & $(\mathrm{mg} / 100 \mathrm{ml})$ & $139 \pm 7$ & $154 \pm 23$ \\
FFA & $(\mathrm{mEq} / \mathrm{l})$ & $0.56 \pm 0.08$ & $0.55 \pm 0.09$ \\
CHO & $(\mathrm{mg} / 100 \mathrm{ml})$ & $126 \pm 36$ & $121 \pm 28$ \\
ALBU & $(\mathrm{g} / \mathrm{l})$ & $3.85 \pm 0.3$ & $3.92 \pm 0.18$ \\
TP & $(\mathrm{g} / \mathrm{l})$ & $6.92 \pm 0.36$ & $7.16 \pm 0.81$ \\
A/G & & $1.27 \pm 0.22$ & $1.28 \pm 0.33$ \\
AST & $(\mathrm{IU} / \mathrm{l})$ & $122 \pm 35$ & $125 \pm 26$ \\
ALT & $(\mathrm{IU} / \mathrm{l})$ & $69.8 \pm 19.6$ & $73.2 \pm 13.4$ \\
TBIL & $(\mathrm{mg} / 100 \mathrm{ml})$ & $0.47 \pm 0.18$ & $0.68 \pm 0.35$ \\
DBIL & $(\mathrm{mg} / 100 \mathrm{ml})$ & $0.27 \pm 0.10$ & $0.43 \pm 0.28$ \\
$\mathrm{IBIL}$ & $(\mathrm{mg} / 100 \mathrm{ml})$ & $0.19 \pm 0.17$ & $0.25 \pm 0.21$ \\
CREA & $(\mathrm{mg} / 100 \mathrm{ml})$ & $0.70 \pm 0.07$ & $0.76 \pm 0.09$ \\
BUN & $(\mathrm{mg} / 100 \mathrm{ml})$ & $17.7 \pm 2.1$ & $18.3 \pm 1.1$ \\
UA & $(\mathrm{mg} / 100 \mathrm{ml})$ & $1.39 \pm 0.29$ & $1.30 \pm 0.34$ \\
LPO & $(\mathrm{nmol} \mathrm{MDA} / \mathrm{ml})$ & $2.88 \pm 1.00$ & $2.44 \pm 0.63$ \\
Ca & $(\mathrm{mg} / 100 \mathrm{ml})$ & $10.4 \pm 1.2$ & $10.7 \pm 1.1$ \\
Fe & $(\mathrm{mg} / \mathrm{l})$ & $1.66 \pm 0.25$ & $1.50 \pm 0.17$ \\
\hline
\end{tabular}

Values are means \pm SD for 8 rats.

naturally occurring lesions were observed in the liver and kidneys at 12 months, but no abnormality due to ingestion of D-psicose was observed (Table 5). Histopathologic observation of the liver at 18 months, revealed fatty degeneration and hepatocellular fibrosis were observed in the D-psicose group and not in the sucrose group (Table 6). These findings tended to be slight and local. The hepatocellular fibrosis observed in one sample of the D-psicose group (out of 8 samples) was extremely mildly. Histopathological observation at 12 months showed no difference in total pathological lesions between the sucrose and the D-psicose groups (Liver, 4.13 vs 3.13; Kidney, 12.3 vs 14.1 (Mean scores)) (Table 5). In the liver at 18 months, the mean value for pathological lesions was significantly higher in the DPsicose group than in the sucrose group (2.75 vs 3.75 (Mean scores)), but the difference was slight $(p<0.0498)$ (Table 6). In the kidneys at 18 months, the total value for pathological lesions did not differ between the sucrose and the D-psicose groups (14.0 vs 14.1 (Mean scores)) (Table 6).

\section{Discussion}

The present study demonstrated that the effects of 3\% Dpsicose in the diet after long-term administration to rats were increased relative weights of liver and kidneys. However, hematological, chemical and histopathological examinations 
Table 5. Histopathological observations of liver and kidneys at 12 months

\begin{tabular}{|c|c|c|c|c|c|c|c|c|c|c|c|c|c|c|c|c|c|c|}
\hline \multirow{2}{*}{$\begin{array}{l}\text { Groups Ra } \\
\text { No. }\end{array}$} & & & \multicolumn{8}{|c|}{ Sucrose } & \multicolumn{8}{|c|}{ D-Psicose } \\
\hline & & & 1 & 2 & 3 & 4 & 5 & 6 & 7 & 8 & 9 & 10 & 11 & 12 & 13 & 14 & 15 & 16 \\
\hline Organs & Findings & & & & & & & & & & & & & & & & & \\
\hline \multirow[t]{5}{*}{ Liver } & Bile duct proliferation & & + & + & + & + & + & + & + & \pm & \pm & + & + & + & + & ++ & - & \pm \\
\hline & Necrosis & & \pm & - & + & + & + & + & \pm & - & \pm & \pm & \pm & \pm & \pm & - & - & \pm \\
\hline & Microgranuloma & & - & \pm & \pm & \pm & \pm & \pm & \pm & + & + & \pm & \pm & - & \pm & - & - & \pm \\
\hline & & Scores $^{\dagger}$ & 3 & 3 & 5 & 5 & 5 & 5 & 4 & 3 & 4 & 4 & 4 & 3 & 4 & 3 & 0 & 3 \\
\hline & & Total score & \multicolumn{8}{|c|}{33} & \multicolumn{8}{|c|}{25} \\
\hline \multirow[t]{7}{*}{ Kidneys } & Basophilic change in the tubule & & + & ++ & \pm & \pm & + & ++ & ++ & ++ & + & ++ & ++ & + & + & + & \pm & ++ \\
\hline & Hyaline cast in the tubule & & + & ++ & \pm & + & ++ & +++ & + & ++ & ++ & +++ & +++ & ++ & ++ & ++ & + & +++ \\
\hline & Brown pigment deposition in the tubule & & ++ & + & + & + & ++ & + & + & + & + & + & \pm & + & ++ & + & ++ & + \\
\hline & Atrophy of the glomerulus & & - & \pm & - & - & - & + & - & - & - & - & - & - & - & + & - & \pm \\
\hline & Hyalinization in the glomerulus & & \pm & + & - & - & + & ++ & \pm & \pm & + & + & ++ & \pm & \pm & + & \pm & + \\
\hline & Thickening of Bowman's capsule basement membrane & & \pm & ++ & \pm & \pm & + & ++ & \pm & + & + & + & ++ & \pm & \pm & ++ & \pm & ++ \\
\hline & Lymphocyte infiltration in the interstitium & & + & ++ & \pm & \pm & \pm & ++ & \pm & ++ & + & ++ & +++ & \pm & + & ++ & \pm & ++ \\
\hline & & Scores ${ }^{\dagger}$ & 11 & 17 & 6 & 7 & 13 & 20 & 10 & 14 & 13 & 16 & 18 & 10 & 12 & 17 & 9 & 18 \\
\hline & & Total score & \multicolumn{8}{|c|}{98} & \multicolumn{8}{|c|}{113} \\
\hline
\end{tabular}

${ }^{+}$Quantify the findings level in each rats; -: 0, $\pm: 1,+: 2,++: 3,+++: 4$.

Table 6. Histopathological observations of liver and kidneys at 18 months

\begin{tabular}{|c|c|c|c|c|c|c|c|c|c|c|c|c|c|c|c|c|c|c|}
\hline \multirow{2}{*}{$\begin{array}{l}\text { Groups Ra } \\
\text { No. }\end{array}$} & & & \multicolumn{8}{|c|}{ Sucrose } & \multicolumn{8}{|c|}{ D-Psicose } \\
\hline & & & 1 & 2 & 3 & 4 & 5 & 6 & 7 & 8 & 9 & 10 & 11 & 12 & 13 & 14 & 15 & 16 \\
\hline Organs & Findings & & & & & & & & & & & & & & & & & \\
\hline \multirow[t]{7}{*}{ Liver } & Bile duct proliferation & & + & + & + & + & + & + & + & + & + & + & \pm & + & \pm & + & + & + \\
\hline & Necrosis & & - & - & - & - & - & - & - & - & - & - & - & + & - & - & - & - \\
\hline & Microgranuloma & & \pm & \pm & \pm & - & \pm & \pm & \pm & - & - & \pm & \pm & \pm & \pm & \pm & \pm & \pm \\
\hline & Fatty degeneration & & - & - & - & - & - & - & - & - & \pm & - & + & - & - & - & + & \pm \\
\hline & Fibrosis with brown pigmentation & & - & - & - & - & - & - & - & - & - & - & - & - & - & - & \pm & - \\
\hline & & Scores $^{\dagger}$ & 3 & 3 & 3 & 2 & 3 & 3 & 3 & 2 & 3 & 3 & 4 & 5 & 2 & 3 & 6 & 4 \\
\hline & & Total score & \multicolumn{8}{|c|}{22} & \multicolumn{8}{|c|}{$30^{*}$} \\
\hline \multirow[t]{7}{*}{ Kidneys } & Basophilic change in the tubule & & ++ & ++ & ++ & ++ & ++ & ++ & ++ & + & ++ & ++ & ++ & ++ & ++ & ++ & ++ & ++ \\
\hline & Hyaline cast in the tubule & & ++ & ++ & ++ & +++ & +++ & +++ & + & ++ & +++ & +++ & +++ & +++ & +++ & +++ & +++ & +++ \\
\hline & Brown pigment deposition in the tubule & & + & + & + & + & + & + & + & + & + & + & + & + & + & + & + & + \\
\hline & Atrophy of the glomerulus & & - & - & - & \pm & \pm & \pm & + & - & \pm & - & \pm & + & \pm & \pm & - & + \\
\hline & Hyalinization in the glomerulus & & \pm & + & \pm & + & + & + & + & \pm & + & + & + & + & + & + & + & ++ \\
\hline & Thickening of Bowman's capsule basement membrane & & \pm & \pm & \pm & + & + & + & + & \pm & + & \pm & + & + & + & + & + & + \\
\hline & Lymphocyte infiltration in the interstitium & & + & \pm & + & + & + & + & + & + & + & + & + & + & + & + & + & + \\
\hline & & Scores $^{\dagger}$ & 12 & 12 & 12 & 16 & 16 & 16 & 17 & 11 & 16 & 14 & 16 & 17 & 16 & 16 & 15 & 18 \\
\hline & & Total score & \multicolumn{8}{|c|}{112} & \multicolumn{8}{|c|}{113} \\
\hline
\end{tabular}

Quantify the findings level in each rats; -: $0, \pm: 1,+: 2,++: 3,+++: 4$.

$*$ Significant difference from the Sucrose group $(* p<0.01$, Student's $t$ tests).

Vol. 45, No. 3, 2009 
revealed no values suggestive of overt D-psicose treatmentrelated toxicity.

Previous testing found that the $\mathrm{LD}_{50}$ value of D-psicose orally in rats was $16 \mathrm{~g} / \mathrm{kg}$ [11]. In the present study, rats actually ingested $1.28 \mathrm{~g} / \mathrm{kg}$ body weight per day of Dpsicose or $1.22 \mathrm{~g} / \mathrm{kg}$ body weight per day of sucrose. Body weight gain and intra-abdominal adipose tissue weight in rats fed the D-psicose diet for 18 months were significantly lower than those in rats fed the sucrose diet. We previously reported that D-psicose supplements suppress hepatic lipogenic enzyme activity and reduce intra-abdominal fat accumulation more effectively than D-glucose or D-fructose supplements in rats $[9,21]$. In addition, we found that Dpsicose is a sweet monosaccharide that provides no energy to growing rats $[8]$. The present findings support our previous results. However, rats fed the D-psicose diet for 12 months did not differ from the sucrose group in most parameters studied, which indicates that D-psicose did not inhibit rat growth. Thus, low dietary levels (3\% of diet or less) of D-psicose over an extended period primarily affected fat accumulation.

In a previous short-term toxicity test in rats, we showed that the feeding of diets extremely high in D-psicose appeared to be harmful to the intestinal tract [11, 22]. Moreover, we previously reported that cecal weight, cecal surface area and cecal content weight increased with increases of D-psicose in diets (above 10\%) [11,22]. D-psicose is partly absorbed in the digestive tract and is excreted into urine and feces. However, it is also fermented in the cecum by intestinal microflora, producing short-chain fatty acids as a soluble dietary fiber $[22,23]$. In this study, no adverse effects on the intestinal tract were seen at $3 \% \mathrm{D}$-psicose in the diet at 12 months. However, cecal content weight in the D-psicose group at 18 months was significantly higher than in the sucrose group. These findings suggest that short-chain fatty acids due to intestinal fermentation accumulated in the cecum during long-term administration of D-psicose. Thus, $3 \%$ D-psicose in the diet does not appear to be harmful to the intestinal tract. Sucralose, a low-calorie artificial sweetener and with the acute-toxicity of the level same as D-psicose, has also been reported to increase cecal weight in the shortterm toxicity test, but this has been recognized as a non-toxic effect [16].

In this study's hematological analysis, dietary D-psicose significantly decreased the $\mathrm{MCH}$ value at 12 months compared to sucrose, and significantly increased the $\mathrm{Hb}$ and MCV values at 18 months. These findings suggest no overt D-psicose toxicity, because the values remain within the normal range.

Dietary D-psicose increased the weights of livers and kidneys. This finding agrees with our previous studies $[10,11,24]$. Bilirubin, a bile pigment, is produced from hemoglobin and is used as an index of hepatic function.
Blood bilirubin concentration increases when hepatopathy and homolytic disease occurs. Blood levels of AST and ALT are also used as indexes of hepatic damages. These values in this study did not differ between D-psicose and sucrose. In addition, histopathologic observations of the liver and kidneys revealed no abnormalities due to ingestion of D-psicose. Liver enlargement occurs in animals and humans under a variety of conditions with different consequences for health [25]. For example, it can be the result of a physiological adaptation to an enhanced workload or metabolic demand, a metabolic abnormality, a toxic effect, an inflammatory process, or a proliferative disease. Bar et al. [26] found that D-tagatose, a rare sugar, increases liver glycogen deposition and relative liver weights in non-fasting rats at dietary levels of $5-20 \%$. D-tagatose is an incompletely absorbed ketohexose (stereo isomer of D-fructose) that has potential as an energy-reduced alternative sweetener. Bar et al. concluded that the liver enlargement seen in response to the consumption of D-tagatose was a physiological response to treatment-induced increased glycogen deposition. We previously found some D-psicose treatmentinduced increase in glycogen deposition (unpublished dates). However, these results lacked clarity. It is unknown whether these mechanisms of the liver enlargement induced by $\mathrm{D}$-psicose and D-tagatose are the same.

Final body weights of both sucrose and D-psicose groups were lower at 18 months than at 12 months. The cause of weight reduction is regarded as a decrease of energy intake by the aging. However, why the weight reduction ratio of D-psicose group is greater than that of sucrose group is not clear.

In conclusion, the present study found the effects of longterm 3\% D-psicose administration to rats to be increased liver and kidney weights with no gross pathological findings correlated with this hypertrophy. Hematological and chemical values were not suggestive of overt D-psicose toxicity. Overall, no adverse effects were seen at this low-dose of D-psicose in the diet.

\section{References}

[1] Cree, G.M. and Perlin, A.S.: O-Isopropylidene derivatives of D-allulose (D-psicose) and D-erythro-hexopyranose-2,3diulose. Can. J. Biochem., 46, 765-770, 1968.

[2] Binkley, W.W.: The fate of cane juice simple sugars during molasses formation. IV. Probable conversion of D-fructose to D-psicose. Int. Sugar J., 65, 105-106, 1963.

[3] Miller, B.S. and Swain, T.: Chromatographic analyses of the free amino acids, organic acids and sugars in wheat plant extracts. J. Sci. Food Agric., 11, 344-348, 1965.

[4] Hough, L. and Stacey, B.E.: Variation in the allitol content of Itea plants during photosynthesis. Phytochemistry, 5, 171$175,1966$.

[5] Eble, T.E., Hoeksema, H., Boyack, G.A., and Savage, G.M.: 
Psicofuranine. I. Discovery, isolation, and properties. Antibiot. Chemother, 9, 419-420, 1959.

[6] Itoh, H., Sato, T., and Izumori, K.: Preparation of D-psicose from D-cructose by immobilized D-tagatose 3-epimerase. $J$. Ferment. Bioeng., 80, 101-103, 1995.

[7] Granström, T.B., Takata, G., Tokuda, M., and Izumori, K.: Izumoring: a novel and complete strategy for bioproduction of rare sugars. J. Biosci. Bioeng., 97, 89-94, 2004.

[8] Matsuo, T., Suzuki, H., Hashiguchi, M., and Izumori, K.: D-Psicose is a rare sugar that provides no energy to growing rats. J. Nutr. Sci. Vitaminol., 48, 77-80, 2002.

[9] Matsuo, T., Baba, Y., Hashiguchi, M., Takeshita, K., Izumori, K., and Suzuki, H.: Less body fat accumulation with Dpsicose diet versus D-fructose diet. J. Clin. Biochem. Nutr., 30, 55-65, 2001.

[10] Matsuo, T. and Izumori, K.: Effects of dietary D-psicose on diurnal variation in plasma glucose and insulin concentrations of rats. Biosci. Biotechnol. Biochem., 70, 2081-2085, 2006.

[11] Matsuo, T., Tanaka, T., Hashiguchi, M., Izumori, K., and Suzuki, H.: Effects of oral acute administration and subchronic feeding of several levels of D-psicose in rats. J. Nutr. Sci. Vitaminol., 48, 512-516, 2002.

[12] Oshima, H., Kimura, I., and Izumori, K.: Synthesis and structure analysis of novel disaccharides containing D-psicose produced by endo-1,4- $\beta$-D-xylanase from Aspergillus sojae. J. Biosci. Bioeng., 101, 280-283, 2006.

[13] Suzuki, M. and Tamura, T.: Sweeteners: low-energetic and low-insulinogenic, in Diet and Obesity, ed. By Bray, G.A., Karger, Basel, pp. 163-173, 1988.

[14] Boesch, C., Ith, M., Jung, B., Bruegger, K., Erban, S., Diamantis, I., Kreis, R., and Bär, A.: Effect of oral Dtagatose on liver volume and hepatic glycogen accumulation in healthy male volunteers. Regul. Toxicol. Pharmacol., 33, 257-267, 2001.

[15] Suzuki, M., Nishiyama, K., Ohmori, S., Yoshioka, M., and Shimomura, Y.: Effects of dietary palatinose and reducedpalatinose on body energy composition. J. Clin. Biochem.
Nutr., 13, 117-125, 1992.

[16] Goldsmith, L.A.: Acute and subchronic toxicity of sucralose. Food Chem. Toxicol., 38, S53-S69, 2000.

[17] Mann, S.W., Yuschak, M.M., Amyes, S.J., Aughton, P., and Finn, J.P.: A combined chronic toxicity/carcinogenic study of sucralose in Spragure-Dawley rats. Food Chem. Toxicol., 38, S71-S89, 2000.

[18] Bergmeyer, H.U. and Bernt, E.: D-Glucose determination with glucose oxidase and peroxidase, in Methods of Enzymatic Analysis, ed. By Bergmeyer, H.U., Academic Press, New York, pp. 1205-1215, 1974.

[19] Fletcher, M.J.: A colorimetric method for estimating serum triglycerides. Clin. Chim. Acta., 22, 393-397, 1968.

[20] Ohkawa, H.: Assay for lipid peroxides in animal tissues by thiobarbituric acid reaction. Anal. Biochem., 95, 351-358, 1979.

[21] Matsuo, T., Baba, Y., Hashiguchi, M., Takeshita, K., Izumori, K., and Suzuki, H.: Dietary D-psicose, a C-3 epimer of Dfructose, suppresses the activity of hepatic lipogenic enzymes in rats. Asia Pac. J. Clin. Nutr., 10, 233-237, 2001.

[22] Matsuo, T., Tanaka, T., Hashiguchi, M., Izumori, K., and Suzuki, H.: Metabolic effects of D-psicose in rats: studies on faecal and urinary excretion and caecal fermentation. Asia Pac. J. Clin. Nutr., 12, 225-231, 2003.

[23] Whistler, R.L., Singh, P.P., and Lake, W.C.: D-psicose metabolism in the rat. Carbohydr. Res., 34, 200-202, 1974.

[24] Matsuo, T. and Izumori, K.: Effects of supplemental Dpsicose on glucose tolerance and serum adipocytokine levels in rats fed a high-fat diet or a low-fat diet. J. Oleo Sci., 53, 453-460, 2004.

[25] Walker, W.A. and Mathis, R.K.: Hepatomegaly: An approach to differential diagnosis. Pediatr. Clin. North Am., 22, 929942, 1975.

[26] Bär, A., Lina, B.A., de Groot, D.M., de Bie, B., and Appel, M.J.: Effect of D-tagatose on liver weight and glycogen content of rats. Regul. Toxicol. Pharmacol., 29, S11-S28, 1999. 